\title{
Study on Government Management Mechanism of Energy Conservation and Emission Reduction
}

\author{
AN JIN-ZHAO \\ School of Management, Northwest University for Nationalities, Lanzhou, P.R. China, 730124 \\ anjinzhao6"<anjinzhao6@163.com
}

\begin{abstract}
Energy conservation and emission reduction is essential to suitable development and economic development in harmony with the environment. Building the government management mechanism of energy conservation and emission reduction has become an important task of government reforms. Study the retraining factors of energy conservation and emission reduction, and propose legal guarantees, management innovation, technology innovation, service system construction and upgrading of industrial structure are the critical factors to energy conservation and emission reduction management mechanism's performance. Then discuss the critical factors deeply. Improve the special legislation, department law linkage and strengthening law enforcement supervision are essential to providing legal guarantees for energy conservation and emission reduction; comprehensive evaluation system and strict control system are essential to management innovation; policy guide and comprehensive utilization is essential to technology innovation; positive policy guide for development of consultation industry is the main task of energy conservation and emission reduction service system construction; high and new technology industries, elimination of outdated production capacity and development of recycling economy are useful for upgrading of industrial structure @ JASEM
\end{abstract}

Today, energy conservation and emission reduction has become a worldwide course of government reforms. China government has done a lot of useful work to construct management system of energy conservation and emission reduction. But the management system of energy conservation and emission reduction has many limitations, and it couldn't meet the need of socioeconomic development in harmony with environment and resources. This study draw lessons form energy conservation and emission reduction experience of developed countries, and propose useful solutions based on the national practical situation. Study the restraining factors of energy conservation and emission reduction comprehensively, and extensively analysis every critical factors' influence on energy conservation and emission reduction. Then, propose the focus on improving the performance of energy conservation and emission reduction in all aspects. The result of this study could provide decision help to the energy conservation and emission reduction management mechanism's optimization. Also could help the government to supervise the energy conservation and emission reduction efficiency of the departments at any levels and determine the focus of work.

Legal guarantees, management innovation, technology innovation, service system construction and upgrading of industrial structure are the critical factors to energy conservation and emission reduction management mechanism's performance. The performance evaluation of government energy conservation and emission reduction system needs a scientific and effective evaluation index system. The index system must consider all corresponding factors restraining the energy conservation and emission reduction's performance. This study determines the index system based on the essential functions of the government management system of energy conservation and emission reduction. And this study's final objective is to form a energy conservation and emission reduction system with government as the guide, whole society as the basis and enterprise as the subject.

Legal Security Mechanism of Energy Conservation and Emission Reduction System: Construction and consummation of energy conservation and emission reduction relevant law could provide measures for government to solve the problem of energy dissipation and environment pollution. The construction and consummation of law related to energy conservation and emission reduction is system engineering. All of the work must be based on the present laws and regulations. Then refine these further. And the refining works must be in connection with the actual need and based on thorough investigation. If necessary, new laws and regulations could come into existence. The construction and consummation must follow in proper sequence, and then could provide a solid legal security foundation.

Construction and consummation of special laws and regulations: Today, our government have more than twenty law related to environment and resources protection. For example, 《Law on Prevention and Control of Water Pollution》、 《Air Pollution Control Law》、 《Law on the Pretension and Control of Noise Pollution》、 《Law on the Pretension and Control of Solid Waste Pollution》、

《Cleaner Production Promotion Law》、 《 Law of Environmental Impact Assessment $\rangle$ and so on. But these laws and regulations couldn't meet the need of energy conservation and emission legal security. 
Relevant industry laws and regulations: Although there is an energy conservation and emission reduction legal security framework, there aren't special laws and regulations related relevant industry and special type of enterprises' energy conservation and emission reduction control. And there aren't effective legal means to closely restraint on enterprises' disposal of pollutants and energy consumption. So, it is necessary to set some corresponding laws and regulations for special industry and enterprises in aspect of saving energy, recycling economic and pollution prevention. For example, the British has many special laws and regulations, 《Alkali Act》、《Industry development Environment Act $\rangle 、 《$ Clean Air Amendment $\rangle$ 、

$\langle$ Fume Emission Act $\rangle$ 、 $\langle$ Environmental Protection Act $\rangle 、 《 W a t e r$ Act $\rangle$ 、 《Water Industry Act $\rangle$ and so on.

Advanced energy conservation and emission system: The developed countries adopt many advanced energy conservation and emission system. First, the system of emission rights trading has been popular in developed countries, and is being tried in some districts in our country. This system should be paid more attention. Enterprises should have the rights of free sale on discharge permit and rights of energy consumption.

Second, the ecology environment compensation system is a wrathful theory in the area of environment resources protecting. At present, there are some ecology environment compensation funds and channels in our country, but no corresponding laws and regulations. The ecology environment compensation's performance doesn't have security.

Linkage of department law: Construction and consummation of energy conservation and emission reduction's laws and regulations, involve many department laws, and it is complicate system engineering. There are a lot of works to do for construction and consummation of administrative law, economic law, and environment law and so on.

Law enforcing supervision: The developed countries' experience shows that it's necessary to set up independent supervision organ besides perfect laws and regulations. The independent supervision organ is responsible for energy conservation and emission reduction supervision. It should be responsible for law enforcing supervision, and strictly investigate and punish the various unlawful practices. So, the problem of overstepping authority and fighting for authority would be solved. The centralized law enforcement is suitable for energy conservation and emission reduction.

* Corresponding author: An Jin-Zhao
Management Innovation Mechanism of Energy Conservation and Emission Reduction System: The management innovation mechanism is an important security for the success of energy conservation and emission reduction.

First, it's essential to construct the energy consumption index system and energy conservation and emission reduction performance evaluation system. The evaluation system would provide the basis for department energy conservation and emission reduction performance examination. It is also necessary to build the information evaluation mechanism for industry's energy conservation and emission reduction, and the information evaluation mechanism would provide decision basis of energy conservation and emission reduction. Consummation of energy conservation and emission reduction management system could provide the security of energy consumption. Set up the energy conservation and emission reduction plan, and decompose the plan into the energy conservation and emission reduction tasks of establishment units.

Reinforce the supervision and control measures, then the energy conservation and emission reduction works could carry on effectively and orderly. Determine the responsibility of the establishment units according to the energy conservation and emission reduction plan and tasks. Strictly examine the achievement of there goals. And during the above process, the comprehensive utilizations of resources should be the focus.

At last, it's useful and essential to collect the suggestions of various establishment units. And optimize the energy conservation and emission reduction management system according to the suggestions and the feedback information of management system's control activities. So the innovation of energy conservation and emission reduction management system would go forward for ever.

Technology Innovation Mechanism of Energy Conservation and Emission Reduction System: The technology is also an important security of energy conservation and emission reduction. Policy guide could help a lot of development of energy conservation and emission reduction technology. Improve the performance of industry and manufacturing high energy-consumption equipments, and use the heat supply, gas supply and power generation combination way, then the performance of energy conservation and emission reduction would be better than ever. Eliminate the backward manufacturing technique and equipment by technique reforms and innovation, and use the advanced manufacturing technique of the world wide. The technique innovation should consider the comprehensive utilization of resources. This way could reduce the harmful substance generation and 
the environment pollution. And the cost would decrease while the benefit would increase. The technique innovation should cover the entire national economic department, especially the department of steel, smelt metal, power and transportation.

Construction of Energy Conservation and Emission Reduction Service System: The energy conservation and emission reduction service system could assure the government' energy conservation and emission reduction target achieved smoothly. The advisory service could provide professional energy conservation and emission reduction advisory. During the energy conservation and emission reduction implementation process, enterprises and public would have many professional problems which couldn't be solved by themselves or the solving cost is too high.

The government should provide a well development environment for advisory service, and provide financial aid. The government also should provide professional train for consultant, and then the business dispositions and the quality of counseling would be better. The government should manage the advisory service effectively, and the advisory qualification examination is necessary for increase the advisory service's level. Use the service system to publicize the energy conservation and emission reduction. Publicize the importance and urgency to raise the saving consciousness and promote the national energy conservation and emission reduction activities. Cultivate the energy conservation and emission reduction consumer fashion and consumption pattern. Finally, form the energy conservation and emission reduction social culture.

Upgrading of Industrial Structure: Upgrading of industrial structure is a phase which must be experienced according to the developed countries' energy conservation and emission reduction experience. Readjust and optimize the industrial structure must consider the distribution characteristics of industry. Eliminate the backward productivity to promote the effective utilization of resources is the main target.

The backward productivity is the main block of the energy conservation and emission reduction. So eliminating the backward productivity could generate considerable energy and reduce considerable pollution discharge amount.

And the industries of steel making, coke, electrolytic aluminum, cement and glass are the focus of upgrading and elimination of backward productivity.
Conclusions: Suggestions on Constructing an Effective Government Management Mechanism of Energy conservation and Emission Reduction: To construct an effective government management mechanism of energy conservation and emission reduction, we should pick up the reform and transformation of government functions in all aspects. Legal guarantees, management innovation, technology innovation, service system construction and upgrading of industrial structure are the critical factors to energy conservation and emission reduction management mechanism's performance. The performance evaluation of government energy conservation and emission reduction system needs a scientific and effective evaluation index system. The index system must consider all corresponding factors restraining the energy conservation and emission reduction's performance. The index system should be based on the essential functions of the government management system of energy conservation and emission reduction. And the final objective is to form a energy conservation and emission reduction system with government as the guide, whole society as the basis and enterprise as the subject.

\section{REFERENCES}

Zhou Jin-rong. A Study on Tax Policy for Promoting Saving Energy and Reducing Emissions. Taxation and Economy. 2009,(3):100-103 (in Chinese)

$\mathrm{Gu}$ Yong-qiang. Multiple Measures of Energy Saving and Discharge Reduction in Germany. Environmental Protection of Oil \& Gas Fields. 2009,(2):54-55 (in Chinese)

Zhang Yan-li, Yang Fan. Practice of Promoting Energy Saving and Emission Reduction by Cleaner Production in Iron \& Steel Enterprises. Environmental Science and Management, 2009,(5):187-189 (in Chinese)

Chen Sha, YANG Shao-hui. Strategies for Energy Saving \& Reduction for Urban Transit Systems. Urban Transport of China. 2009,(3):48-52 (in Chinese)

Ren Guang-dong, TIAN Yue-feng. Application of the Energy Conservation,Emission Reduction and Cleaner Production in Surface Treatment Industry. Plating \& Finishing, 2009, (4):43-46 (in Chinese) 
Zhang Bi-guang, GAO Jian-min, YI Song-lin, WANG Tian-long. The present research situation of solar-heat pump and heat pipe technology on lumber drying in China. Journal of North China Electric Power University(Natural Science Edition), 2009, (3):43-44 (in Chinese)

LV Wei-qi. Energy Saving Potential in PAN Fiber Industry and Technical Measures. Synthetic Fiber in China, 2009, (4):51-53 (in Chinese)

Guo Run-sheng. On Target Management of Saving Energy and Reducing Effluent in Oilfield Enterprise. Journal of Sinopec Management Institute, 2008, (4):64-66 (in Chinese)

Shi Tao. Research on Economic Phenomenon About Energy Conservation and Emission Reduction in Huzhou City. Journal of Huzhou Vocational and Technological College, 2009, (1):72-76 (in Chinese)
Zhou Guang-de. Design \& applied research of building energy conservation. China Building Materials Science \& Technology, 2009, (2):65-66 (in Chinese)

TAO Lun-kang. The Ethics Foundation of Legislation for Energy Conservation and Reduced Emissions. Plating \& Finishing, 2009, (5):7-12 (in Chinese)

Li Shen. Wastewater Treatment Innovation and Energy Saving and Pollution Reduction in a Dyeing and Finishing Plant. Textile Dyeing and Finishing Journal, 2009, (6):41-44 (in Chinese)

Zhang Yong-jia. EMC Model and Its Generalization and Application in the Cause of Energy-saving and Emission Reduction. Shenhua Science and Technology, 2009, (1):91-94 (in Chinese) 